\title{
Implantable loop recorders in patients with unexplained syncope: Clinical predictors of pacemaker implantation
}

\author{
Martin Huemer, Ann-Kristin Becker, Alexander Wutzler, Philipp Attanasio,
} Abdul Parwani, Philipp Lacour, Leif-Hendrik Boldt, Burkert Pieske, Wilhelm Haverkamp, Florian Blaschke

Department of Cardiology, Campus Virchow-Klinikum, Charité - University Medicine Berlin, Germany

\begin{abstract}
Background: Implantable loop recorders (ILR) are a valuable tool for the investigation of unexplained syncopal episodes. The aim of this retrospective single center study was to identify predictive factors for pacemaker implantation in patients with unexplained syncope who underwent ILR insertion.

Methods: One hundred six patients were retrospectively analyzed (mean age 59.1 years; $47.2 \%$ male) with unexplained syncope and negative conventional testing who underwent ILR implantation. The primary study endpoint was detection of symptomatic or asymptomatic bradycardia requiring pacemaker implantation.

Results: The average follow-up period after ILR implantation was $20 \pm 15$ months. Pacemaker implantation according to current guidelines was necessary in 22 (20.8\%) patients, mean duration until index bradycardia was $81 \pm 88$ (2-350) days. Ten (45.5\%) patients received a pacemaker due to sinus arrest, 7 (31.8\%) patients due to third-degree atrioventricular block, 2 (9.1\%) patients due to seconddegree atrioventricular block and 1 (4.5\%) patient due to atrial fibrillation with a slow ventricular rate. Three factors remained significant in multivariate analysis: obesity, which defined by a body mass index above $30 \mathrm{~kg} / \mathrm{m}^{2}$ (OR: 7.39, $\left.p=0.014\right)$, a right bundle branch block (OR: 9.40, $p=0.023$ ) and chronic renal failure as defined by a glomerular filtration rate of less than $60 \mathrm{~mL} / \mathrm{min}$ (OR: 6.42, $p=0.035$ ). Conclusions: Bradycardia is a frequent finding in patients undergoing ILR implantation due to unexplained syncope. Obesity, right bundle branch block and chronic renal failure are independent clinical predictors of pacemaker implantation. (Cardiol J 2019; 26, 1: 36-46)
\end{abstract}

Key words: implantable loop recorder, unexplained syncope, pacemaker

\section{Introduction}

Syncope is common in the general population and is an important clinical problem with adverse outcomes from associated physical trauma, negative impact on life quality and increased cardiovascular risk $[1,2]$. In addition, the investigation of syncope imposes a significant economic burden on society [3]. With a cumulative lifetime incidence of about $40 \%$ [4], syncope accounts for $1-3 \%$ of emergency department visits [1].

To investigate the underlying cause of syncope is often a difficult task, because underlying abnormalities are usually not present at the time of clinical evaluation. The European Society of Cardiology (ESC) guidelines for the diagnosis and management of syncope highlight the use of implantable loop recorders (ILRs) by including ILRs in

Address for correspondence: Martin Huemer, MD, Charité — Universitätsmedizin Berlin Campus Virchow-Klinikum Medizinische Klinik mit Schwerpunkt Kardiologie Augustenburger Platz 1, D-13553 Berlin, Germany, tel: +49-30-450 665 411, fax: +49-30-450 565 900, e-mail: martin.huemer@charite.de 
class I recommendations for an evaluation of recurrent unexplained syncope, either in the early phase in non-high risk patients or after a comprehensive workup in high risk patients [5]. The ability of ILRs to continuously monitor cardiac rhythm over long periods makes them powerful diagnostic tools for patients with unexplained syncope [6]. Using ILRs, in the majority of patients a diagnosis can be established by performing long-term symptom rhythm correlation [7-9]. Cardiac arrhythmias as primary cause of syncopes are common and most of them are caused by bradyarrhythmic events [10]. In cases of recurrent syncopal events due to bradyarrhythmia, pacemaker (PM) implantation significantly improves patient symptoms and prognosis [11]. Study data on possible predictive factors for bradycardia requiring PM implantation in patients with unexplained syncope receiving an ILR is limited [12, 13].

The aim of the present study was to identify clinical predictors of significant bradycardia requiring PM implantation in patients who underwent ILR implantation due to unexplained syncope.

\section{Methods}

\section{Study design}

The present study is a retrospective single center study, including patients who received an ILR due to unexplained syncope after conventional diagnostic work-up. A comprehensive review of patient charts was performed to identify possible clinical predictive factors for PM implantation due to bradyarrhythmias in the study population. The study protocol was approved by the human ethics committee of the Charite - Universitätsmedizin Berlin (ethic application number: EA1/234/14). All patients gave their written informed consent for scientific data analyses on a retrospective basis at hospital admission.

\section{Study population}

The study population included all consecutive patients referred to this institution (Department of Cardiology, University Hospital Charité) between February 2009 and August 2014, who underwent ILR implantation for further investigation of unexplained syncope. The diagnostic algorithm prior to ILR implantation included clinical evaluation, a 12-lead surface electrocardiogram (ECG) and echocardiography and, if considered appropriate, coronary angiography or cardiac stress testing, Holter monitoring, invasive electrophysiology and cardiac magnetic resonance imaging (cMRI).
Details on the extent of conventional and special diagnostic tests are outlined in Table 1A. Clinical data for anamneses, features of the syncopal episodes, demographics, comorbidities, laboratory results, ECG parameters, echocardiographic findings and concomitant medical treatment were collected from the medical records stored on the hospital database (Tables $1 \mathrm{~A}$ and $1 \mathrm{~B}$ ). Patients with coronary artery disease, valvular heart disease stage $\geq$ II, cardiomyopathy (HCM, DCM, ARVC), septum hypertrophy $\geq 14 \mathrm{~mm}$ or left ventricular ejection fraction (LVEF) $<55 \%$ were included under the term 'structural heart disease'. Moderate to severe structural heart disease was defined as valvular heart disease stage $\geq$ II or LVEF $<45 \%$.

After hospital discharge all patients had routinely ILR interrogations at 4-month intervals at the documented outpatient clinic. In addition, patients had follow-up after each event suggestive for bradyarrhythmic or tachyarrythmic episodes to analyze stored ILR data.

\section{ILR implantation}

The ILR implantation in the present study population was performed by a cardiologist at this institution. At the time of implantation automatic activation was programmed to detect bradyarrhythmias $(<40 \mathrm{bpm})$ and tachyarrhythmias (> $170 \mathrm{bpm}$ ). Automatic algorithms for detection of atrial fibrillation (AF) were activated if available. The following types of ILR were used: 47 (44.3\%) patients received a Reveal ${ }^{\oplus} \mathrm{DX} 9528$ (Medtronic, Minneapolis, MN, USA), 44 (41.5\%) patients a Reveal ${ }^{\oplus}$ XT 9529 (Medtronic, Minneapolis, MN, USA), 5 (4.7\%) patients a Confirm $^{\mathrm{TM}}$ (St. Jude Medical, St. Paul, MN, USA) and $10(9.4 \%)$ patients a BioMonitor (Biotronik, Berlin, Germany). Patients were instructed to activate the ILR manually in case of symptoms.

\section{Study end points}

Primary end point of this study was implantation of a PM due to documented bradyarryhthmic events. Within the ILR baseline detection setting bradyarrhythmic events were defined either by pauses of more than $3 \mathrm{~s}$ or by a heart rate of less than $40 \mathrm{bpm}$. Tachyarrhythmic episodes were defined as ventricular heart rate of more than $170 \mathrm{bpm}$. Secondary endpoint included syncope recurrence, $\mathrm{AF}$ and flutter and ventricular tachycardia after the index event.

\section{PM implantation}

Pacemaker implantation due to documented bradycardia was performed according to the ESC 
Table 1A and B. Baseline demographic and clinical characteristics of the study population before insertion of an implantable loop recorder.

Table 1A

\begin{tabular}{|c|c|c|c|c|}
\hline Parameter & $\begin{array}{l}\text { All patients } \\
(\mathrm{n}=106)\end{array}$ & $\begin{array}{l}\text { Patients with PM } \\
\qquad(\mathrm{n}=22)\end{array}$ & $\begin{array}{l}\text { Patients without PM } \\
\qquad(\mathrm{n}=84)\end{array}$ & $\mathbf{P}$ \\
\hline \multicolumn{5}{|l|}{ Study population } \\
\hline Age [years] & $59.12 \pm 17.49(21-89)$ & $62.18 \pm 12.68(32-76)$ & $58.32 \pm 18.52(21-89)$ & 0.588 \\
\hline Age $\geq 75$ years & $19(8.4 \%)$ & $3(13.6 \%)$ & $16(19.0 \%)$ & 0.758 \\
\hline Male gender & $50(47.17 \%)$ & $10(45.5 \%)$ & $40(47.6 \%)$ & 1 \\
\hline Female gender & $56(52.83 \%)$ & $12(54.5 \%)$ & $44(52.4 \%)$ & 1 \\
\hline Hight [cm] & $170.13 \pm 8.63(152-200)$ & $170.64 \pm 8.56(158-190)$ & $170.00 \pm 8.697(152-200)$ & 0.734 \\
\hline Hight male [cm] & $175.06 \pm 8.58(156-200)$ & $175.60 \pm 9.13(158-190)$ & $174.93 \pm 8.56(156-200)$ & 0.658 \\
\hline Hight female $[\mathrm{cm}]$ & $165.73 \pm 5.90(152-184)$ & $166.50 \pm 5.54(158-176)$ & $165.52 \pm 6.04(152-184)$ & 0.581 \\
\hline $\mathrm{BMI}>30 \mathrm{~kg} / \mathrm{m}^{2}$ & $22(20.8 \%)$ & $11(50.0 \%)$ & $11(13.1 \%)$ & $<0.001$ \\
\hline BMI $\left[\mathrm{kg} / \mathrm{m}^{2}\right]$ & $26.39 \pm 5196(17.3-42.1)$ & $30.03 \pm 5.21(22.4-40.5)$ & $25.43 \pm 4.78(17.3-42.1)$ & $<0.001$ \\
\hline BMI male $\left[\mathrm{kg} / \mathrm{m}^{2}\right]$ & $28.03 \pm 5.23(19.5-42.1)$ & $30.66 \pm 4.87(22.4-37.7)$ & $27.37 \pm 5.17(19.5-42.1)$ & 0.056 \\
\hline BMI female $\left[\mathrm{kg} / \mathrm{m}^{2}\right]$ & $24.92 \pm 4.747(17.3-40.5)$ & $29.51 \pm 5.63(23.1-40.5)$ & $23.67 \pm 3.64(17.3-34.1)$ & 0.001 \\
\hline \multicolumn{5}{|l|}{ Cardiologic work-up } \\
\hline Clinical examination & $106(100 \%)$ & $22(100 \%)$ & $84(100 \%)$ & 1 \\
\hline Holter ECG & $83(78.3 \%)$ & $17(81.0 \%)$ & $66(80.5 \%)$ & 1 \\
\hline Echocardiography & $106(100 \%)$ & $22(100 \%)$ & $84(100 \%)$ & 1 \\
\hline Stress echocardiography & $10(9.6 \%)$ & $3(14.3 \%)$ & $7(8.4 \%)$ & 0.418 \\
\hline Ergometry & $34(32.1 \%)$ & $7(33.3 \%)$ & $27(32.5 \%)$ & 1 \\
\hline Coronary angiography & $91(85.8 \%)$ & $21(95.5 \%)$ & $70(83.3 \%)$ & 0.067 \\
\hline Electrophysiology testing & $38(35.8 \%)$ & $9(42.9 \%)$ & $29(34.9 \%)$ & 0.613 \\
\hline \multicolumn{5}{|c|}{ Laboratory findings before ILR implantation } \\
\hline Creatinin $[\mathrm{mg} / \mathrm{dL}]$ & $1.003 \pm 0.72(0.54-7.54)$ & $1.07 \pm 0.49(0.64-2.41)$ & $0.99 \pm 0.77(0.54-7.54)$ & 0.357 \\
\hline GFR $[\mathrm{mL} / \mathrm{min}]$ & $77.58 \pm 22.18(6.84-133.68)$ & $71.456 \pm 26.81(23.95-133.68)$ & $79.18 \pm 20.69(6.84-133.01)$ & 0.134 \\
\hline $\mathrm{GFR}<60 \mathrm{~mL} / \mathrm{min}$ & $21(19.8 \%)$ & $10(45.5 \%)$ & $11(13.1 \%)$ & 0.002 \\
\hline $\mathrm{Hb}[\mathrm{g} / \mathrm{dL}]$ & $13.70 \pm 1.31(9.2-17.5)$ & $13.60 \pm 1.28(11.3-15.7)$ & $13.73 \pm 1.322(9.2-17.5)$ & 0.562 \\
\hline $\mathrm{TSH}[\mathrm{mU} / \mathrm{L}]$ & $1.49 \pm 1.03(0.01-6.52)$ & $1.82 \pm 1.41(0.57-6.52)$ & $1.41 \pm 0.92(0.01-4.64)$ & 0.24 \\
\hline Potassium [mmol/L] & $4.045 \pm 0.37(3.1-5.9)$ & $4.047 \pm 0.307(3.4-4.6)$ & $4.045 \pm 0.38(3.1-5.9)$ & 0.669 \\
\hline \multicolumn{5}{|l|}{ ECG characteristics } \\
\hline Right bundle branch block & $8(7.7 \%)$ & $5(23.8 \%)$ & $3(3.6 \%)$ & 0.008 \\
\hline Left bundle branch block & $4(3.8 \%)$ & 0 & $4(4.8 \%)$ & 1 \\
\hline Left anterior hemiblock & $6(5.8 \%)$ & $1(4.8 \%)$ & $5(6.0 \%)$ & 0.580 \\
\hline Left posterior hemiblock & 0 & 0 & 0 & - \\
\hline $\begin{array}{l}\text { Intraventricular conduction } \\
\text { delay }\end{array}$ & 0 & 0 & $2(2.4 \%)$ & 1 \\
\hline Any bundle branch block & $20(18.9 \%)$ & $6(27.3 \%)$ & $14(16.7 \%)$ & 0.229 \\
\hline First degree AVB & $11(10.6 \%)$ & $2(9.5 \%)$ & $9(10.8 \%)$ & 1 \\
\hline Heart rate $[\mathrm{bpm}]$ & $70.70 \pm 15.24(38-118)$ & $70.52 \pm 14.71(52-118)$ & $70.747 \pm 15.46(38-118)$ & 0.843 \\
\hline PR interval [ms] & $164.47 \pm 30.28(120-268)$ & $169.33 \pm 29.53(124-252)$ & $163.32 \pm 30.53(120-268)$ & 0.322 \\
\hline QRS duration [ms] & $95.92 \pm 20.697(60-186)$ & $100.68 \pm 18.46(76-146)$ & $94.80 \pm 21.14(60-186)$ & 0.082 \\
\hline OT duration [ms] & $402.11 \pm 37.73(304-510)$ & $411.78 \pm 34.14(336-466)$ & $399.76 \pm 38.395(304-510)$ & 0.158 \\
\hline QTc duration [ms] & $423.54 \pm 43.81(98-570)$ & $432.32 \pm 25.16(380-487)$ & $421.48 \pm 47.02(98-570)$ & 0.144 \\
\hline
\end{tabular}


Table 1B.

\begin{tabular}{|c|c|c|c|c|}
\hline Parameter & $\begin{array}{l}\text { All patients } \\
(n=106)\end{array}$ & $\begin{array}{l}\text { Patients with PM } \\
\quad(n=22)\end{array}$ & $\begin{array}{l}\text { Patients without PM } \\
\text { (n= 84) }\end{array}$ & $\mathbf{P}$ \\
\hline \multicolumn{5}{|c|}{ Associated cardiovascular and neurological disorders } \\
\hline TIA or stroke & $15(14.2 \%)$ & $3(13.6 \%)$ & $12(14.3 \%)$ & 1 \\
\hline Diabetes type II & $19(17.9 \%)$ & $5(22.7 \%)$ & $14(16.7 \%)$ & 0.538 \\
\hline Arterial hypertension & $67(63.8 \%)$ & $19(86.4 \%)$ & $48(57.8 \%)$ & 0.013 \\
\hline Metabolic syndrome & $27(25.5 \%)$ & $10(45,5 \%)$ & $17(20,2 \%)$ & 0.026 \\
\hline Systolic BP [mmHg] & $122.88 \pm 17.07(80-170)$ & $126.19 \pm 17.99(80-162)$ & $122.048 \pm 16.84(90-170)$ & 0.137 \\
\hline Diastolic BP [mmHg] & $73.47 \pm 10.64(50-100)$ & $77.24 \pm 13.74(55-100)$ & $72.52 \pm 9.57(50-95)$ & 0.121 \\
\hline Congestive heart failure & $18(17.1 \%)$ & $3(13.6 \%)$ & $15(18.1 \%)$ & 0.759 \\
\hline Atrial fibrillation & $29(27.6 \%)$ & $10(45.5 \%)$ & $19(22.9 \%)$ & 0.058 \\
\hline Coronary heart disease & $26(28.3 \%)$ & $7(31.8 \%)$ & $19(27.1 \%)$ & 0.787 \\
\hline $\begin{array}{l}\text { Cardiomyopathy (HCM, } \\
\text { DCM, ARVC) }\end{array}$ & $7(6.6 \%)$ & $1(4.5 \%)$ & $6(7.1 \%)$ & 1 \\
\hline Structural heart disease & $47(44.3 \%)$ & $11(50.0 \%)$ & $36(42.9 \%)$ & 0.632 \\
\hline $\begin{array}{l}\text { Moderate to severe } \\
\text { structural heart disease }\end{array}$ & $17(16.0 \%)$ & $3(13.6 \%)$ & $14(16.7 \%)$ & 1.0 \\
\hline LVEF [\%] & $57.60 \pm 6.45(35-72)$ & $56.59 \pm 6.05(40-65)$ & $57.87 \pm 6.55(35-72)$ & 0.544 \\
\hline LVEF normal & $88(73.6 \%)$ & $19(86.3 \%)$ & $69(80.1 \%)$ & 0.567 \\
\hline LVEF slightly reduced & $14(13.2 \%)$ & $4(18.2 \%)$ & $10(11.9 \%)$ & 0.482 \\
\hline LVEF moderat reduced & $4(3.8 \%)$ & $1(4.5 \%)$ & $3(3.6 \%)$ & 1 \\
\hline LVEF highly reduced & 0 & 0 & 0 & - \\
\hline $\begin{array}{l}\text { Second or higher degree } \\
\text { valve defect }\end{array}$ & $14(14.4 \%)$ & $3(14.3 \%)$ & $11(14.5 \%)$ & 1 \\
\hline Left ventricular hypertrophy & $47(44.3 \%)$ & $13(59.1 \%)$ & $34(46.6)$ & 0.339 \\
\hline Septal diameter $[\mathrm{mm}]$ & $12.17 \pm 4.10(6-32)$ & $12.10 \pm 1.83(9-15)$ & $12.20 \pm 4.53(6-32)$ & 0.321 \\
\hline \multicolumn{5}{|l|}{ Concomittant medication } \\
\hline Beta-blocker & $58(54.7 \%)$ & $16(72.7 \%)$ & $42(50.0 \%)$ & 0.091 \\
\hline ACEI & $36(34 \%)$ & $7(31.8 \%)$ & $29(34.5 \%)$ & 1 \\
\hline AT1-blockers & $31(29.2 \%)$ & $11(50.0 \%)$ & $20(23.8 \%)$ & 0.033 \\
\hline Aldosterone antagonist & $2(1.9 \%)$ & 0 & $2(2.4 \%)$ & 1 \\
\hline Digitalis & $1(0.9 \%)$ & 0 & $1(1.2 \%)$ & 1 \\
\hline Class III anti-arrhythmic drugs & $1(0.9 \%)$ & 0 & $1(1.2 \%)$ & 1 \\
\hline Class I anti-arrhythmic drugs & 0 & 0 & 0 & - \\
\hline Calcium channel blockers & $23(21.7 \%)$ & $8(36,4 \%)$ & $15(17.9 \%)$ & 0.081 \\
\hline Diuretics & $33(31.1 \%)$ & $10(45.5 \%)$ & $23(27.4 \%)$ & 0.124 \\
\hline \multicolumn{5}{|l|}{ Syncope anamnesis } \\
\hline Additional presyncopes & $43(40.6 \%)$ & $9(40.9 \%)$ & $34(40.5 \%)$ & 0.971 \\
\hline 1 syncope & $17(16.0 \%)$ & $2(9.1 \%)$ & $15(17.9 \%)$ & 0.809 \\
\hline 2-3 syncopes & $34(32.1 \%)$ & $7(31.81 \%)$ & $27(32.1 \%)$ & 0.809 \\
\hline 4-5 syncopes & $15(14.2 \%)$ & $3(13.6 \%)$ & $12(14.3 \%)$ & 0.809 \\
\hline$>5$ syncopes & $40(37.7 \%)$ & $9(40.9 \%)$ & $31(36.9 \%)$ & 0.809 \\
\hline Trauma during syncope & $46(56.8 \%)$ & $8(50,0 \%)$ & $38(58.5 \%)$ & 0.583 \\
\hline Family history of syncopes & $13(15.7 \%)$ & $2(11,1 \%)$ & $11(16.9 \%)$ & 0.724 \\
\hline $\begin{array}{l}\text { Family history of unexplained } \\
\text { sudden death }\end{array}$ & $12(13.6 \%)$ & $1(5,6 \%)$ & $11(15.7 \%)$ & 0.446 \\
\hline Prodromal symptoms & $64(64.0 \%)$ & $13(61.9 \%)$ & $51(64.6 \%)$ & 0.804 \\
\hline Diziness & $39(39.0 \%)$ & $9(42.9 \%)$ & $30(38.0 \%)$ & 0.802 \\
\hline Nausea & $14(14.0 \%)$ & $3(14.3 \%)$ & $11(13.9 \%)$ & 1 \\
\hline Emesis & $1(1.0 \%)$ & $0(0.0 \%)$ & $1(1.3 \%)$ & 1 \\
\hline Impaired vision & $11(11.0 \%)$ & $3(14.3 \%)$ & $8(10.1 \%)$ & 0.695 \\
\hline Perspiration & $13(13.0 \%)$ & $1(4.8 \%)$ & $12(15.2 \%)$ & 0.290 \\
\hline Sensation of cold & 0 & 0 & 0 & - \\
\hline Palpipation & $19(17.9 \%)$ & $3(14.3 \%)$ & $16(20.3 \%)$ & 0.536 \\
\hline
\end{tabular}

Data are presented as number (percentage) or mean \pm standard deviation (range). ACEI - angiotensin-converting enzyme inhibitor;

ARVC - arrhy-thmogenic right ventricular cardiomyopathy; AT1-blockers - angiotensin II receptor antagonists; AVB - atrioventricular block; BMI - body mass index; BP - blood pressure; DCM - dilated cardiomyopathy; ECG - electrocardiogram; GFR - glomerular filtration rate; $\mathrm{Hb}$ - hemoglobin; $\mathrm{HCM}$ - hypertrophic cardiomyopathy; LVEF — left ventricular ejection fraction; TIA — transient ischemic attack; $\mathrm{TSH}$ - thyroid-stimulating hormone; PM — pacemaker 
guidelines for cardiac pacing and cardiac resynchronization therapy $[11,14]$ in the following cases: 1) Patients with symptoms which can clearly be attributed to ILR documented bradycardia. Symptoms included syncope, presyncope, dizziness, angina pectoris and dyspnoe. 2) Patients with a documented bradycardia during a possible reflex syncope and pauses due to sinus arrest or atrioventricular block (AV block) longer than $6 \mathrm{~s}$. 3) Patients with a relevant but asymptomatic bradycardia documented by ILR. Following bradyarrhythmias were considered significant even in the absence of symptoms: Sinus arrest due to sinus dysfunction with pauses $\geq 3$ s with an exception of young trained persons, during sleep and when bradycardia is induced by concomitant drugs; Mobitz II second-degree AV block or third-degree AV block, AF with slow ventricular conduction leading to intermittent pauses of at least $3 \mathrm{~s}$ during day time without reversible cause.

\section{Statistical analysis}

Mean values \pm standard deviation (SD) and range were reported to describe continuous variables. Percentages were presented to report categorical variables. For univariate testing differences between PM and non-PM implantation patients were analyzed by Mann-Whitney U-test for non-normally distributed variables. Categorical variables were compared using the Fisher exact test. Thereafter a multivariate stepwise logistic regression analysis was performed to identify clinical predictors of PM implantation. Univariate and multivariate analyses were adjusted by age and gender. Kaplan-Meier survival curves were used to present time course to syncopal recurrence and to occurrence of bradyarrhythmia. All p-values are two-sided, and a p-value of $<0.05$ was considered to be statistically significant. All analyses were performed using SPSS $^{\circledR}$ for Windows Version 22.0 (SPSS Inc.).

\section{Results}

\section{Patient population}

Between February 2009 and August 2014 a total of 106 patients (age $59.1 \pm 17.5 ; 50$ [47.2\%] male) met the inclusion criteria of this study. Demographic characteristics and comorbidities of the study population group are shown in Tables $1 \mathrm{~A}$ and $1 \mathrm{~B}$. Amongst the study population, Holter monitoring (24 h to 5 days) was done in $83(78.3 \%$ ) patients. Coronary angiography was performed in 91 (85.8\%) patients to exclude coronary artery disease. Stress echocardiography was performed in $10(9.6 \%)$ and ergometry in $34(32.1 \%)$ patients. There were 38 (35.8\%) patients who had electrophysiology testing performed prior to ILR insertion. The majority of patients $(88 ; 73.6 \%)$ had normal LVEF, 14 (13.2\%) patients had slightly reduced LVEF and only $4(3.8 \%)$ patients had moderately reduced LVEF. Forty-six (56.8\%) patients had a trauma secondary to syncope. Eighty-nine (83.7\%) patients experienced two or more syncopal episodes prior to ILR insertion. Twelve (13.6\%) patients had a family history of sudden cardiac death. Atrial fibrillation was known before ILR implantation in 29 (27.6\%) patients. The mean PR interval was $164.6 \pm 30.3 \mathrm{~ms}$ with no significant difference $(\mathrm{p}=0.322)$ between the group receiving a PM $(169.3 \pm 29.5 \mathrm{~ms})$ and the group not receiving a PM $(169.3 \pm 30.5 \mathrm{~ms})$. Mean heart rate (HR) at ILR implantation was $70.7 \pm 15.2 \mathrm{bpm}$. All patient characteristics used for univariate analyses are depicted in Tables $1 \mathrm{~A}$ and $1 \mathrm{~B}$.

\section{Follow-up. Data and study endpoints}

Details on patient follow-up are depicted in Figure 1. Mean follow-up in this study population was $19.8 \pm 15.4(0.1-58.8)$ months. No death was recorded in the study population during the follow-up period. Overall, diagnosis is based on the ILR was made in $46(43.4 \%)$ patients. The most common diagnosis was non-arrhythmic syncope (19 patients). In $22(20.8 \%)$ patients a PM was implanted due to documented bradyarrhythmic episodes, of whom $10(45.5 \%)$ patients were male (age $62.2 \pm 12.7$ years). The median time from ILR insertion to documented bradycardia and consecutive PM implantation was $81 \pm 88$ (range 2 to 350 ) days. Ten (45.5\%) patients had a PM implanted for sinus arrest, $2(9.1 \%)$ patients had a second-degree AV block, 7 (31.8\%) patients showed third-degree AV block and 1 (4.5\%) patient had AF with a slow ventricular rate. In $10(45.5 \%)$ patients a PM was implanted due to syncope recurrence with documented significant bradyarrhythmic episodes, whereas in $12(54.5 \%)$ patients significant bradycardia was considered an indication for PM implantation even in the absence of symptoms. Two $(9.1 \%)$ patients suffered from a recurrent syncope after PM implantation.

In $5(4.7 \%)$ patients, new tachyarrhythmic episodes were found during ILR monitoring. In 3 (2.8\%) of these patients paroxysmal supraventricular tachycardia (AV-nodal reentry tachycardia, atrial flutter) was recorded, which was successfully treated by catheter ablation. In 1 patient a paroxysmal 


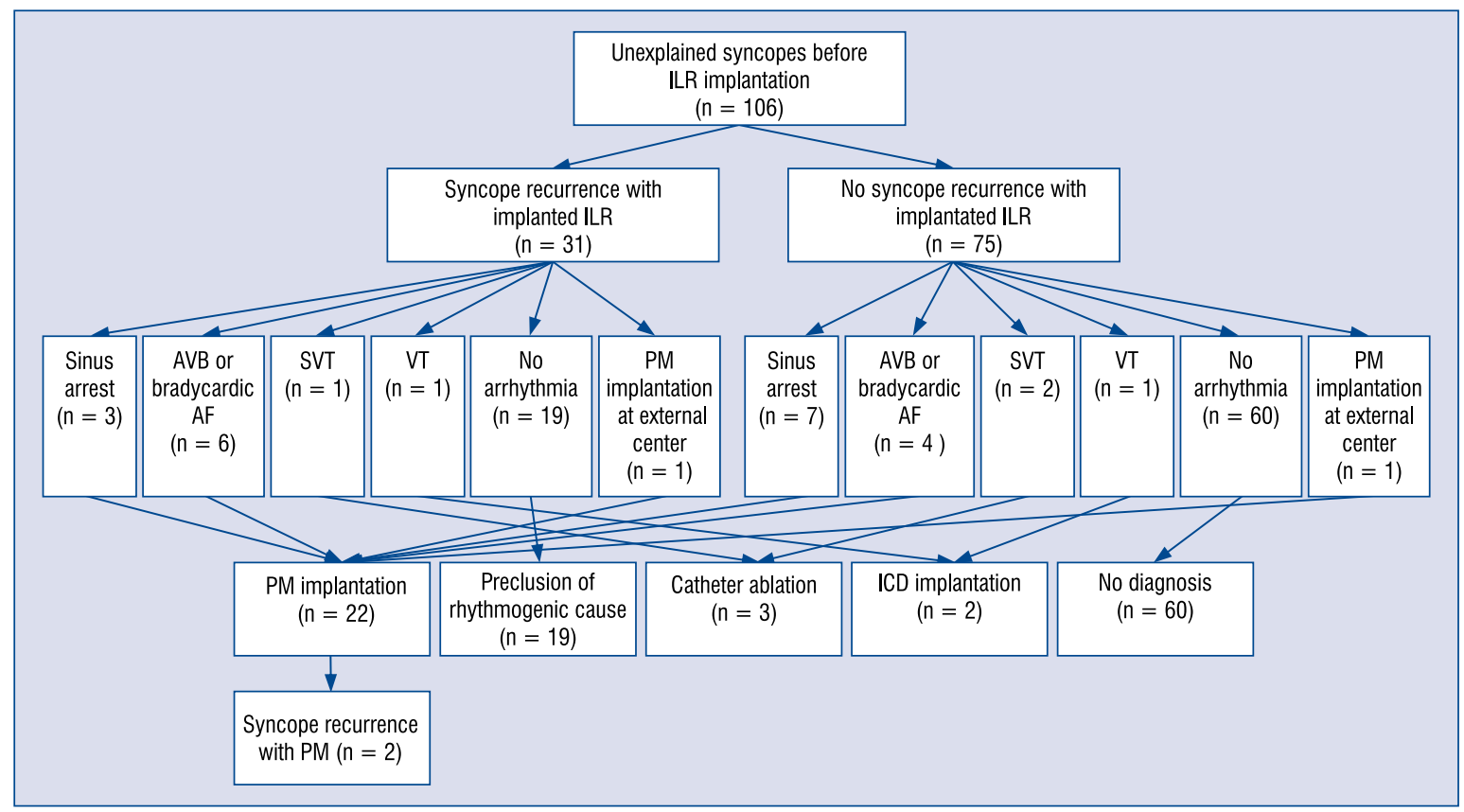

Figure 1. Follow-up data of the overall study population after implantable loop recorder (ILR) implantation; AF — atrial fibrillation; AVB — atrioventricular block; ICD — implantable cardioverter-defibrillator; PM — pacemaker; SVT — supraventricular tachycardia; VT — ventricular tachycardia.

supraventricular tachycardia was associated with syncope recurrence. Two (1.9\%) patients underwent implantable cardioverter-defibrillator (ICD) implantation because of documented ventricular tachycardia. In $4(3.8 \%)$ patients an oral anticoagulation therapy was initiated due to first time detection of AF or atrial flutter. Figure 2 depicts the time course of diagnosis, either exclusion of an arrhythmogenic cause due to syncopal recurrence without documented rhythm disorders (Fig. 2A) or documentation of relevant bradyarrhythmic events necessitationg PM implantation (Fig. 2B).

\section{Clinical predictors of PM implantation}

In the univariate analyses, (Table 2 ) the following factors were associated with PM implantation after additional adjustment for gender and age: obesity, defined by a body mass index (BMI) above $30 \mathrm{~kg} / \mathrm{m}^{2}$ (odds ratio [OR]: 8.096; 95\% confidence interval [CI] 2.619-25.023; $\mathrm{p}<0.001$ ), renal failure with a glomerular filtration rate (GFR) of less than $60 \mathrm{~mL} / \mathrm{min}$ calculated using the CockcroftGault formula (OR: 6.147; 95\% CI 1.857-20.352; $\mathrm{p}=0.003)$, a right bundle branch block (RBBB) (OR: 8.058; 95\% CI 1.740-37.327; $\mathrm{p}=0.008$ ), arterial hypertension (OR: 6.255; 95\% CI 1.332 $-29.378 ; \mathrm{p}=0.020)$, medical treatment with
AT1-receptor blockers (OR: 3.254; 95\% CI $1.085-9.753 ; \mathrm{p}=0.035)$ and the metabolic syndrome (OR: 3.262; 95\% CI 1.147-9.275; $\mathrm{p}=0.027$ ).

Variables which were significant predictors of PM implantation in univariate analysis were further analyzed by a multivariate regression analysis. From six factors which were determined by multivariate regression analysis, the following factors were identified as independent predictive factors of PM implantation (Table 2): Obesity, defined by a BMI above $30 \mathrm{~kg} / \mathrm{m}^{2}$ (OR: 7.388; $95 \%$ CI 1.495-36.506; $\mathrm{p}=0.014$ ), a RBBB (OR: 9.401; 95\% CI 1.357-65.117; $\mathrm{p}=0.023)$ and renal failure with a GFR of less than $60 \mathrm{~mL} / \mathrm{min}$ [2] (OR: 6.420; 95\% CI 1.156-35.655; $\mathrm{p}=0.035$ ).

The rate of PM implantation according to the presence of risk factor in the present study population is displayed in Figure 3. A combination of two or more predictors significantly increased the rate of PM implantation.

\section{Discussion}

The current study aimed to identify clinical predictors of bradycardia necessitating PM implantation in patients with unexplained syncope during ILR monitoring. In the present study, bradycardia 


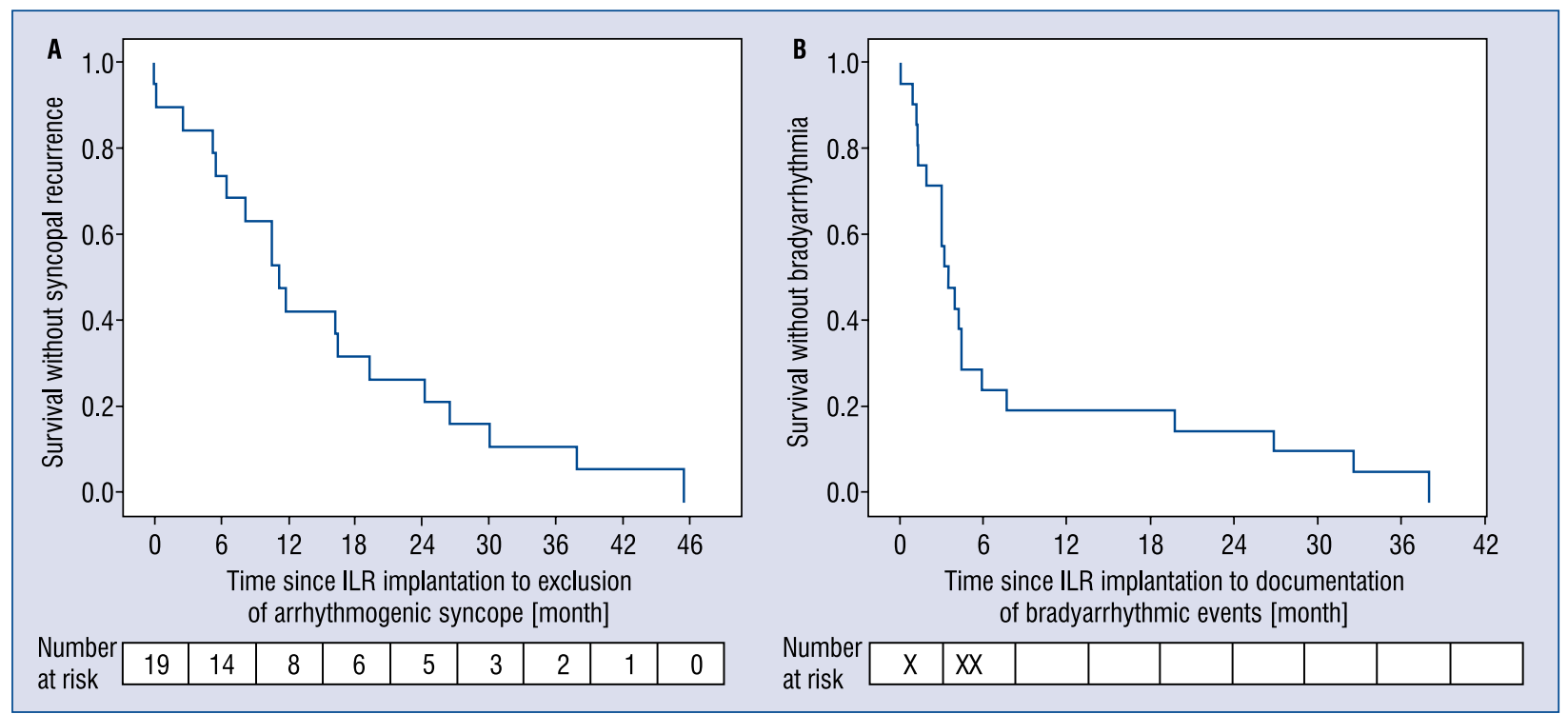

Figure 2. Time course after implantable loop recorder (ILR) insertion of exclusion of an arrrhythmogenic cause due to syncopal recurrence without documented rhythm disorders $(\mathbf{A})$ and time course of documented relevant bradyarrhythmia necessitating pacemaker implantation (B).

Table 2. Predictors of pacemaker implantation in the overall study population according to odds ratio (OR) calculated by univariate and multivariate analysis.

\begin{tabular}{lcccccc}
\hline Variable & \multicolumn{3}{c}{ Univariate analysis* } & \multicolumn{3}{c}{ Multivariate analysis } \\
\cline { 2 - 7 } & OR & $95 \% \mathrm{Cl}$ & $\mathbf{p}$ & OR & $95 \% \mathrm{Cl}$ & $\mathbf{p}$ \\
\hline $\mathrm{BMI}>30 \mathrm{~kg} / \mathrm{m}^{2}$ & 8.096 & $2.619-25.023$ & $<0.001$ & 7.388 & $1.495-36.506$ & 0.014 \\
$\mathrm{GFR}<60 \mathrm{~mL} / \mathrm{min}$ & 6.147 & $1.857-20.352$ & 0.003 & 6.42 & $1.156-35.655$ & 0.035 \\
Right bundle branch block & 8.058 & $1.740-37.327$ & 0.008 & 9.401 & $1.357-65.117$ & 0.023 \\
Arterial hypertension & 6.255 & $1.332-29.378$ & 0.02 & 4.064 & $0.611-27.041$ & 0.147 \\
AT1-blockers & 3.254 & $1.085-9.753$ & 0.035 & 1.05 & $0.205-5.380$ & 0.954 \\
Metabolic syndrome & 3.262 & $1.147-9.275$ & 0.027 & 0.43 & $0.078-2.358$ & 0.331 \\
\hline
\end{tabular}

*Adjusted for age and sex; BMI — body mass index; $\mathrm{Cl}$ — confidence interval; GFR — glomerular filtration rate

requiring $\mathrm{PM}$ implantation was found in 22 out of 106 patients $(20.8 \%)$. This proportion is comparable to previous published data $(14-21 \%)[9,15]$. The overall diagnosis rate was higher than reported by others $(43.4 \%)$, whereas data from large registries reveal a final diagnosis in approximately $30 \%$ of the patients $[9,12,13,15]$.

Obesity, chronic renal failure with a GFR $<60$ $\mathrm{mL} / \mathrm{min}$ and $\mathrm{RBBB}$ were identified as significant independent clinical predictors of PM implantation. In addition, the existence of two or more predictors significantly increased the rate of PM implantations. All three identified risk factors are possible markers for an underlying medical condition that may be associated with an impairment of the electrical impulse generating and conduction system of the heart.

\section{Chronic renal failure}

A negative impact of chronic kidney disease (CKD) on cardiac function and alterations of cardiac rhythm stability has been known for a long time. The cardiorenal syndrome refers to the interconnection of heart and kidney dysfunctions and is related to poor clinical outcomes [16]. Chronic kidney disease has been shown to be a risk factor of sudden cardiac death caused by cardiomyopathy, myocardial inflammation, myocardial fibrosis, arrhythmias and conduction abnormalities [17, 18]. Sudden cardiac death in patients with chronic renal failure is associated with increased levels of inflammatory markers such as high-sensitivity C-reactive protein and interleukin 6 which are both linked to fibrotic changes of the myocardium and the electrical conduction system itself [19]. Previ- 


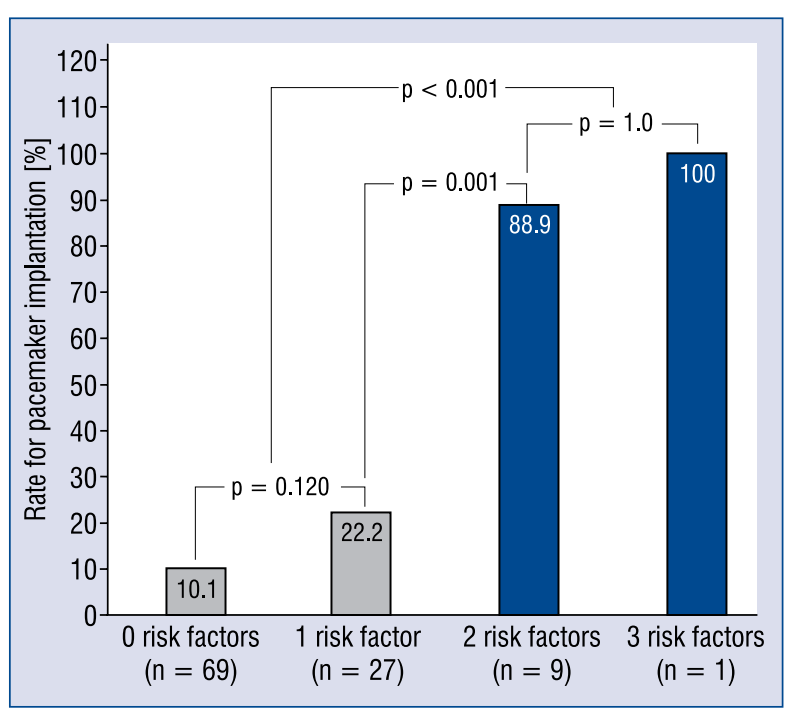

Figure 3. Risk of pacemaker implantation in the overall study population according to the number of independent predictive risk factors. A combination of two or more predictors significantly increased the risk of pacemaker implantation.

ous studies reported that CKD is independently associated with alterations in left atrial function (left atrial volume and atrial strain rate) as well as ventricular strain rates, both markers for myocardial fibrosis [20, 21]. Accordingly, cMRI studies revealed myocardial fibrotic alterations in patients with CKD [22]. Based on these alterations in myocardial interstitial structure chronic changes in sinus node function and cardiac conduction system are reasonable [23, 24]. However, renal failure has not been identified as an independent risk factor for bradyarrhythmic events as yet. In the present study a highly significant association between PM implantation and bradyarrhythmic event in patients with a GFR of less than $60 \mathrm{~mL} / \mathrm{min}$ was found, this measurement is defined as cutoff for a CKD stage 3 .

\section{Obesity and metabolic syndrome}

Several studies have demonstrated an association between obesity and cardiac arrhythmias with increased risk of sudden cardiac death and $\operatorname{AF}[25,26]$. Obesity is associated with pathological myocardial changes such as myocyte hypertrophy, fibrosis, focal myocardial disarray, fatty infiltration, and increased epicardial fat [27]. The effect of myocardial fibrosis on sinus node function and the electrical conduction system has been described previously [28]. Thus, previous animal studies have shown that metabolic syndrome and obesity induce alterations of sinus node function due to fat accumulation around nodal cardiomyocytes and changes in sympathetic innervation [29, 30]. Moreover, obesity associated increased leptin and reduced adiponectin levels might also contribute to increased atrial fibrosis [31]. Amongst the present study population 10 (9.4\%) patients had PM implanted due to sinus arrest.

Long-term effects of myocardial fibrosis on the electrical conduction systems have been described in the context of various cardiac diseases. Thus, functional alterations in the AV-node associated with increased fibrosis were reported in animal models of heart failure [32]. In a large-scale Australian cohort study the risk of hospitalization with a primary diagnosis of AV block has been shown to significantly increase with an increment of BMI [33]. In addition to structural changes as an underlying cause of sinus node and electrical conduction system dysfunction in obese patients, functional alterations associated with sleep apnea have also been documented in these patients [34,35] severe sleep apnea is a known risk factor of sudden cardiac death. However, the role of bradyarrhythmias in patients with severe sleep apnea and a potential beneficial effect of PM therapy in patients with prolonged episodes of asystole is still controversial [35]. Amongst the present study population, sleep apnea induced bradycardia is rather unlikely as bradyarrhythmic episodes necessitating PM implantation occurred solely during daytime. Among this study population 9 (8.5\%) patients had PM implanted for AV block.

\section{Right bundle branch block}

The 2013 ESC guidelines on cardiac pacing state that PM implantation may be considered in selected patients with unexplained syncope and bundle branch block (BBB) (recommendation class IIb) [11]. The Bradyarrhythmia detection in the BBB (B4) Study analyzed the clinical outcomes of patients with syncope and BBB followed a systematic diagnostic approach, including electrophysiological study and ILR implantation [36]. Although the most common cause of syncope in these patients was bradyarrhythmia, mostly due to paroxysmal AV block, other etiologies of syncope were identified in $17.6 \%$ of the study population. The PRESS Study, a prospective multicenter study randomized 101 patients with bifascicular block and unexplained syncope implanted with a dual chamber PM to either DDD pacing mode with a $60 \mathrm{ppm}$ lower rate or DDI mode with $30 \mathrm{ppm}$ lower rate [37]. The use of a dual chamber PM programmed to DDD $60 \mathrm{ppm}$ led to 
a significant reduction of the combination of syncope/presyncope compared with DDI $30 \mathrm{ppm}$ programming [37]. The composite primary end point occurred in 23 patients, whereas only 14 patients developed a class I indication for permanent pacing during the course of the study. In addition, several studies focusing on the outcome of patients with bifascicular block and previous syncope reported consistent rates of AV block development over time [38]. However, none of these studies was designed to identify clinical predictors of bradyarrhythmic events necessitating PM implantation. In the present group of syncopal patients, the incidence of left bundle branch block (LBBB) was relatively low, which might explain why statistical significance was not achieved in this subgroup. Moreover, in elderly patients with LBBB and unexplained syncope, PM implantation was often the therapy of choice in the present institution instead of ILR implantation.

\section{Comparison of previous studies evaluating predictors of PM implantation}

Several studies analyzed the effectiveness of ILRs or prolonged monitoring in predicting the cause of syncope, reporting a diagnostic yield up to $78 \%$ [9, 39-41]. However, only few studies were specifically designed to identify clinical predictors of bradycardia requiring PM implantation in patients with unexplained syncope undergoing ILR monitoring. Previous work by Palmisano et al. [12] identified age $>75$ years, a history of trauma secondary to syncope and asymptomatic bradycardia as independent predictive factors for bradyarrhythmias necessitating PM implantation in patients receiving an ILR due to unexplained syncope. In addition, Ahmed et al. [13] recently found that age $>75$ years, female sex, a history of injury secondary to syncope and a prolongation of the PR interval over $200 \mathrm{~ms}$ are independent predictors of PM implantation in these patients.

Differences between the present results and previous studies are probably related to the relatively small cohort of patients and high heterogeneity. Thus, the present study and work by Palmisano et al. [12] and Ahmed et al. [13] differs in terms of patient characteristics, clinical work-up preceding ILR implantation, cohort size, type and programming of implanted ILRs. Palmisano et al. [12] enrolled 56 patients with a mean age of 68.1 years (61\% male), whereas our study population included 106 patients with a mean age of 59.1 years $(50 \%$ male). Thus, the rates of PM implants were also analyzed in this study cohort in patients $<75$ years vs. patients $\geq 75$ years and no statistically significant difference was found. A possible explanation for this finding might be that older patients were treated with syncope and particularly those with subsequent traumatic injury and a lower threshold for implanting a PM instead of considering ILR monitoring.

In the study population of Palmisano et al. [12] only 11 patients had bradyarrhythmic events necessitating PM implantation, which may have led to an overinterpretation of the validity in identified predictive factors. The study population of Ahmed et al. [13] consisted of 200 patients with a mean age of 61.7 years ( $45 \%$ male). However, compared to Ahmed et al. [13] the frequency of hypertension, diabetes and coronary artery disease in the present study population was higher and the incidence of $\mathrm{RBBB}$ and LBBB was lower.

\section{Clinical impact}

As previous studies have shown that recurrent syncope increases both mortality and morbidity [42], early diagnosis and timely therapeutic intervention is essential in patients presenting with unexplained syncope. ILRs have been shown to be a useful and cost-effective tool in the diagnosis for patients with unexplained syncope $[41,43$, 44], however this method has the drawback of a prolonged period of observation with possible syncopal recurrences before diagnosis and therapeutic intervention.

As a cardiac cause of syncope was established in $22.4 \%$ of syncopal patients with ILR (128 out of 570) in the PICTURE (Place of Reveal in the Care pathway and Treatment of patients with unexplained Recurrent Syncope) registry [9], in identification of predictors of arrhythmic syncope, it is important to identify patients at higher risk of developing future bradyarrhythmic events. A risk stratification for patients with unexplained syncope based on predictive factors which can easily be assessed during the initial work-up might help to identify patients necessitating PM implantation and thereby expedite timely device therapy.

\section{Limitations of the study}

The study presented here has two main limitations. First, it is retrospective single center analysis of a relatively small cohort of patients. Second, overall RBBB was documented in only $8(7.7 \%)$ patients. Thus, despite the statistical significance the relatively small number of patients with $\mathrm{RBBB}$ may have introduced bias in to the interpretation of the results. 


\section{Conclusions}

The present study identified patients in a population receiving ILR due to unexplained syncope obesity, RBBB and chronic renal failure with a GFR $<60 \mathrm{~mL} / \mathrm{min}$ as independent predictors of future bradyarrhythmic events requiring $\mathrm{PM}$ implantation. Moreover, a combination of two or more of these predictive factors significantly increased the risk of PM implantation. Thus, PM implantation might be directly considered in patients if all identified predictive factors are present to reduce mortality and morbidity associated with recurrent syncope. However, a large prospective, multicenter study is necessary to corroborate these findings.

\section{Conflict of interest: None declared}

\section{References}

1. Soteriades ES, Evans JC, Larson MG, et al. Incidence and prognosis of syncope. N Engl J Med. 2002; 347(12): 878-885, doi: 10.1056/NEJMoa012407, indexed in Pubmed: 12239256.

2. Rose MS, Koshman ML, Spreng S, et al. The relationship between health-related quality of life and frequency of spells in patients with syncope. J Clin Epidemiol. 2000; 53(12): 1209-1216, indexed in Pubmed: 11146266.

3. Sutton R, Benditt DG. Epidemiology and economic impact of cardiac syncope in western countries. Future Cardiol. 2012; 8(3): 467-472, doi: 10.2217/fca.12.17, indexed in Pubmed: 22642635.

4. Colman N, Nahm K, Ganzeboom KS, et al. Epidemiology of reflex syncope. Clin Auton Res. 2004; 14 Suppl 1: 9-17, doi: 10.1007/ s10286-004-1003-3, indexed in Pubmed: 15480937.

5. Moya A, Sutton R, Ammirati F, et al. Task Force for the Diagnosis and Management of Syncope, European Society of Cardiology (ESC), European Heart Rhythm Association (EHRA), Heart Failure Association (HFA), Heart Rhythm Society (HRS). Guidelines for the diagnosis and management of syncope (version 2009). Eur Heart J. 2009; 30(21): 2631-2671, doi: 10.1093/eurheartj/ ehp298, indexed in Pubmed: 19713422.

6. Parry SW, Matthews IG. Implantable loop recorders in the investigation of unexplained syncope: a state of the art review. Heart. 2010; 96(20): 1611-1616, doi: 10.1136/hrt.2010.193417, indexed in Pubmed: 20937748.

7. Paruchuri V, Adhaduk M, Garikipati NV, et al. Clinical utility of a novel wireless implantable loop recorder in the evaluation of patients with unexplained syncope. Heart Rhythm. 2011; 8(6): 858-863, doi: 10.1016/j.hrthm.2011.01.039, indexed in Pubmed: 21296683.

8. Farwell DJ, Freemantle N, Sulke N. The clinical impact of implantable loop recorders in patients with syncope. Eur Heart J. 2006; 27(3): 351-356, doi: 10.1093/eurheartj/ehi602, indexed in Pubmed: 16314338.

9. Edvardsson N, Frykman V, van Mechelen R, et al. PICTURE Study Investigators. Use of an implantable loop recorder to increase the diagnostic yield in unexplained syncope: results from the PICTURE registry. Europace. 2011; 13(2): 262-269, doi: 10.1093/europace/euq418, indexed in Pubmed: 21097478.
10. Brignole M, Sutton R, Menozzi C, et al. Early application of an implantable loop recorder allows effective specific therapy in patients with recurrent suspected neurally mediated syncope. Eur Heart J. 2006; 27(9): 1085-1092, doi: 10.1093/eurheartj/ehi842, indexed in Pubmed: 16569653.

11. Brignole M, Auricchio A, Baron-Esquivias G, et al. 2013 ESC Guidelines on cardiac pacing and cardiac resynchronization therapy: the Task Force on cardiac pacing and resynchronization therapy of the European Society of Cardiology (ESC). Developed in collaboration with the European Heart Rhythm Association (EHRA). Eur Heart J. 2013; 34(29): 2281-2329, doi: 10.1093/ eurheartj/eht150, indexed in Pubmed: 23801822.

12. Palmisano P, Accogli M, Zaccaria M, et al. Predictive factors for pacemaker implantation in patients receiving an implantable loop recorder for syncope remained unexplained after an extensive cardiac and neurological workup. Int J Cardiol. 2013; 168(4): 3450-3457, doi: 10.1016/j.jicard.2013.04.179, indexed in Pubmed: 23701932.

13. Ahmed N, Frontera A, Carpenter A, et al. Clinical Predictors of Pacemaker Implantation in Patients with Syncope Receiving Implantable Loop Recorder with or without ECG Conduction Abnormalities. Pacing Clin Electrophysiol. 2015; 38(8): 934-941, doi: 10.1111/pace.12666, indexed in Pubmed: 25973599.

14. Vardas PE, Auricchio A, Blanc JJ, et al. European Society of Cardiology, European Heart Rhythm Association. Guidelines for cardiac pacing and cardiac resynchronization therapy: The Task Force for Cardiac Pacing and Cardiac Resynchronization Therapy of the European Society of Cardiology. Developed in collaboration with the European Heart Rhythm Association. Eur Heart J. 2007; 28(18): 2256-2295, doi: 10.1093/eurheartj/ehm305, indexed in Pubmed: 17726042.

15. Lacunza-Ruiz FJ, Moya-Mitjans A, Martínez-Alday J, et al. Implantable loop recorder allows an etiologic diagnosis in one-third of patients. Results of the Spanish reveal registry. Circ J. 2013; 77(10): 2535-2541, indexed in Pubmed: 23877732.

16. Anand IS. Cardiorenal syndrome: a cardiologist's perspective of pathophysiology. Clin J Am Soc Nephrol. 2013; 8(10): 1800-1807, doi: 10.2215/CJN.04090413, indexed in Pubmed: 23886565.

17. Shamseddin MK, Parfrey PS. Sudden cardiac death in chronic kidney disease: epidemiology and prevention. Nat Rev Nephrol. 2011; 7(3): 145-154, doi: 10.1038/nrneph.2010.191, indexed in Pubmed: 21283136.

18. Sherif KA, Abo-Salem E, Panikkath R, et al. Cardiac repolarization abnormalities among patients with various stages of chronic kidney disease. Clin Cardiol. 2014; 37(7): 417-421, doi: 10.1002/ clc.22277, indexed in Pubmed: 25043948.

19. Parekh RS, Plantinga LC, Kao WH, et al. The association of sudden cardiac death with inflammation and other traditional risk factors. Kidney Int. 2008; 74(10): 1335-1342, doi: 10.1038/ ki.2008.449, indexed in Pubmed: 18769368.

20. Kadappu KK, Kuncoro AS, Hee L, et al. Chronic kidney disease is independently associated with alterations in left atrial function. Echocardiography. 2014; 31(8): 956-964, doi: 10.1111/ echo.12503, indexed in Pubmed: 24447093.

21. Panoulas VF, Sulemane S, Konstantinou K, et al. Early detection of subclinical left ventricular myocardial dysfunction in patients with chronic kidney disease. Eur Heart J Cardiovasc Imaging. 2015; 16(5): 539-548, doi: 10.1093/ehjci/jeu229, indexed in Pubmed: 25428945. 
22. Edwards NC, Moody WE, Yuan M, et al. Diffuse interstitial fibrosis and myocardial dysfunction in early chronic kidney disease. Am J Cardiol. 2015; 115(9): 1311-1317, doi: 10.1016/j. amjcard.2015.02.015, indexed in Pubmed: 25769628.

23. Adar A, Kiriş A, Ulusoy S, et al. Fragmented QRS is associated with subclinical left ventricular dysfunction in patients with chronic kidney disease. Acta Cardiol. 2014; 69(4): 385-390, doi: 10.2143/AC.69.4.3036654, indexed in Pubmed: 25181913.

24. Laszki-Szcząchor K, Zwolińska D, Sobieszczańska M, et al. Dynamics of changes in heart conduction system in dialyzed young adults after kidney transplantation--pilot study. Transplant Proc. 2014; 46(8): 2708-2713, doi: 10.1016/.j.transproceed.2014.09.038, indexed in Pubmed: 25380900.

25. Hubert HB, Feinleib M, McNamara PM, et al. Obesity as an independent risk factor for cardiovascular disease: a 26-year followup of participants in the Framingham Heart Study. Circulation. 1983; 67(5): 968-977, indexed in Pubmed: 6219830.

26. Dublin S, French B, Glazer NL, et al. Risk of new-onset atrial fibrillation in relation to body mass index. Arch Intern Med. 2006; 166(21): 2322-2328, doi: 10.1001/archinte.166.21.2322, indexed in Pubmed: 17130384.

27. Abel ED, Litwin SE, Sweeney G. Cardiac remodeling in obesity. Physiol Rev. 2008; 88(2): 389-419, doi: 10.1152/physrev.00017.2007, indexed in Pubmed: 18391168.

28. Csepe TA, Kalyanasundaram A, Hansen BJ, et al. Fibrosis: a structural modulator of sinoatrial node physiology and dysfunction. Front Physiol. 2015; 6: 37, doi: 10.3389/fphys.2015.00037, indexed in Pubmed: 25729366.

29. Albarado-Ibañez A, Avelino-Cruz JE, Velasco M, et al. Metabolic syndrome remodels electrical activity of the sinoatrial node and produces arrhythmias in rats. PLoS One. 2013; 8(11): e76534, doi: 10.1371/journal.pone.0076534, indexed in Pubmed: 24250786.

30. Yanni J, Tellez JO, Sutyagin PV, et al. Structural remodelling of the sinoatrial node in obese old rats. J Mol Cell Cardiol. 2010; 48(4): 653662, doi: 10.1016/.j.yjmcc.2009.08.023, indexed in Pubmed: 19729016.

31. Shin SY, Yong HS, Lim HE, et al. Total and interatrial epicardial adipose tissues are independently associated with left atrial remodeling in patients with atrial fibrillation. J Cardiovasc Electrophysiol. 2011; 22(6): 647-655, doi: 10.1111/j.15408167.2010.01993.x, indexed in Pubmed: 21235672.

32. Yanni J, Maczewski M, Mackiewicz U, et al. Structural and functional alterations in the atrioventricular node and atrioventricular ring tissue in ischaemia-induced heart failure. Histol Histopathol. 2014; 29(7): 891-902, doi: 10.14670/HH-29.891, indexed in Pubmed: 24368587.

33. Joshy G, Korda RJ, Attia J, et al. Body mass index and incident hospitalisation for cardiovascular disease in 158546 participants from the 45 and Up Study. Int J Obes (Lond). 2014; 38(6): 848 -856, doi: 10.1038/ijo.2013.192, indexed in Pubmed: 24149770.

34. Grimm W, Becker HF. Obesity, sleep apnea syndrome, and rhythmogenic risk. Herz. 2006; 31(3): 213-8; quiz 219, doi: 10.1007/ s00059-006-2800-3, indexed in Pubmed: 16770557.

35. Schweitzer P. Cardiac arrhythmias in obstructive sleep apnea. Vnitr Lek. 2008; 54(10): 1006-1009.

36. Moya A, García-Civera R, Croci F, et al. Diagnosis, management, and outcomes of patients with syncope and bundle branch block. Eur Heart J. 2011; 32(12): 1535-1541, doi: 10.1093/eurheartj/ ehr071, indexed in Pubmed: 21444367.

37. Santini M, Castro A, Giada F, et al. Prevention of syncope through permanent cardiac pacing in patients with bifascicular block and syncope of unexplained origin: the PRESS study. Circ Arrhythm Electrophysiol. 2013; 6(1): 101-107, doi: 10.1161/ CIRCEP.112.975102, indexed in Pubmed: 23390123.

38. Tabrizi F, Rosenqvist M, Bergfeldt L, et al. Time relation between a syncopal event and documentation of atrioventricular block in patients with bifascicular block: clinical implications. Cardiology. 2007; 108(2): 138-143, doi: 10.1159/000096038, indexed in Pubmed: 17028424.

39. Sud S, Klein GJ, Skanes AC, et al. Predicting the cause of syncope from clinical history in patients undergoing prolonged monitoring. Heart Rhythm. 2009; 6(2): 238-243, doi: 10.1016/j. hrthm.2008.10.035, indexed in Pubmed: 19187918.

40. Kadmon E, Menachemi D, Kusniec J, et al. Clinical experience of two Israeli medical centers with the implantable loop recorder in patients with syncope: from diagnosis to treatment. Isr Med Assoc J. 2012; 14(8): 488-492, indexed in Pubmed: 22977968.

41. Furukawa T, Maggi R, Bertolone C, et al. Additional diagnostic value of very prolonged observation by implantable loop recorder in patients with unexplained syncope. J Cardiovasc Electrophysiol. 2012; 23(1): 67-71, doi: 10.1111/j.1540-8167.2011.02133.x, indexed in Pubmed: 21777327.

42. Solbiati M, Bozzano V, Barbic F, et al. Syncope recurrence and mortality: a systematic review. Europace. 2015; 17(2): 300-308, doi: 10.1093/europace/euu327, indexed in Pubmed: 25476868.

43. Martínez P, Pilar Sáez M, Rubio JA, et al. [Experience with the use of an implantable loop recorder in a series of older people with falls and suspected arrhythmic syncopes]. Rev Esp Geriatr Gerontol. 2014; 49(3): 121-124, doi: 10.1016/j.regg.2013.07.005, indexed in Pubmed: 24548525.

44. Davis S, Westby M, Pitcher D, et al. Implantable loop recorders are cost-effective when used to investigate transient loss of consciousness which is either suspected to be arrhythmic or remains unexplained. Europace. 2012; 14(3): 402-409, doi: 10.1093/europace/eur343, indexed in Pubmed: 22071383. 